\title{
Formação continuada de professores da educação superior: novas linguagens, novas práticas, novos desafios
}

\author{
Sandra Gomes \& Manuel Tavares
}

\begin{abstract}
Resumo
O texto que apresentamos pretende ser uma reflexão, a partir da literatura ajustada à temática, sobre a formação continuada de professores da educação superior e os desafios que se lhes colocam numa sociedade globalizada, infiltrada pelas políticas neoliberais que invadiram também o mundo educativo. Refletimos sobre as novas linguagens impostas pelas agências internacionais de regulação, em tempos de globalização, e que têm implicações nos processos educativos e nas concepções sobre educação. Consideramos ser importante sugerir, a partir de um conjunto de autores, a superação do professor monocultural e a exigência de um novo professor - multicultural -, capaz de promover a interculturalidade na sua prática pedagógica. Para isso, se torna necessário a articulação entre pesquisa e prática pedagógica. Percorremos alguns textos de Cortesão, Nóvoa, Sousa Santos e Walsh que conosco refletiram sobre as diversas temáticas abordadas. Consideramos que o pensamento de Freire, abordado no final do texto, se encontra numa linha de consonância com as perspectivas dos autores anteriormente referidos. O texto apresentado não contempla uma dimensão empírica, constituindo um suporte teórico para um trabalho de pesquisa de campo em curso.
\end{abstract}

Palavras-chave:

educação superior; formação continuada; multiculturalismo; interculturalismo; neoliberalismo. 


\section{Continued Education of Higher Education Professors: New Languages, new Practices and new Challenges}

Abstract: The text we present intends to be a reflection, based on the literature adjusted to the theme, on the continuing education of teachers of higher education and the challenges facing them in a globalized society, infiltrated by neoliberal policies that also invaded the educational world. We reflect on the new languages imposed by the international regulatory agencies, in times of globalization, and that have implications in educational processes and conceptions about education. We consider very important to suggest, from a group of authors, the overcoming of the monocultural teacher and the demand of a new professor - multicultural -, capable of promoting interculturality in his pedagogical practice. For this, the articulation between research and pedagogical practice becomes necessary. We have gone through some texts by Cortesão, Nóvoa, Sousa Santos and Walsh, who reflected on the different themes addressed. We consider that Freire's thinking, on which we reflect at the end of the text, is in line with the perspectives of the authors mentioned. The text does not contemplate an empirical dimension, constituting a theoretical support for an ongoing field research work.

Key-words: higher education; continuing education; multiculturalism; interculturalism; neoliberalism.

\section{La Formation continue des enseignants de la éducation supérieur: les nouveaux langages, nouvelles pratiques et nouveaux défis}

Résumé: Le texte que nous présentons c'est un reflet de la littérature sur le thème de la formation continue des enseignants de l'enseignement supérieur et les défis qui nous attendent dans une société mondialisée, infiltré par les politiques néo-libérales qui ont également envahi le monde de l'éducation. Nous réfléchissons sur les nouveaux langages imposés par les organismes de régulation internationaux, à l'époque de la mondialisation, qui ont des implications dans les processus éducatifs et dans les concepts de l'éducation. Nous considérons qu'il est important de proposer, à partir d'un groupe d'auteurs, surmontant l'enseignant monoculturel et l'exigence d'un nouvel enseignant - multiculturel - capable de promouvoir l'interculturalisme dans leur pratique pédagogique. Pour cela, il est nécessaire de lier la recherche et la pratique de l'enseignement. Nous avons recherché quelques textes par Cortesão, Nóvoa, Sousa Santos et Walsh. Nous réfléchissons, avec eux, sur les différentes questions abordées. Nous croyons que la pensée de Freire, dont nous faisons une réflexion à la fin du texte, il est dans la même perspective de ces auteurs.

Mots-clés: enseignement supérieur; formation continue; multiculturalisme; interculturalisme; néolibéralisme.

\section{La Formación continua de los profesores de la educación superior: los nuevos lenguajes, nuevas practicas y nuevos retos}

Resumen: El texto que presentamos es un reflejo de la literatura sobre el tema de la formación continua de los profesores de la educación superior y los desafíos que tienen por delante en una sociedad globalizada, infiltrada por las políticas neo-liberales que también invadieron el mundo educativo. Se reflexiona sobre los nuevos lenguajes impuestos por los organismos reguladores internacionales, en tiempos de la globalización, que tienen implicaciones en los procesos de enseñanza y sobre las concepciones de educación. Consideramos que es importante sugerir, a partir de un grupo de autores, la superación del profesor monocultural y la exigencia de un nuevo profesor - multicultural - capaz de promover la interculturalidad en su enseñanza. Para esto, es necesario vincular la investigación a la practica docente. Hemos investigado algunos textos de Cortesão, Nóvoa, Sousa Santos y Walsh los cuales nos han permitido reflexionar sobre los diversos temas tratados. Creemos que el pensamiento de Freire, del cual hacemos una breve reflexión al final del texto, está en una línea de acuerdo con las perspectivas de estos autores.

Palabras clave: Educación superior; educación continua; multiculturalismo; interculturalidad; neoliberalismo. 


\section{Introdução}

Quando tínhamos todas as respostas, mudaram as perguntas. Esta é uma afirmação inscrita num mural, em Quito, e reproduzida por Galeano. Parece-nos adequada à problemática sobre a qual refletiremos no presente texto. Os professores da educação superior, no âmbito do paradigma dominante de educação e das práticas pedagógicas tradicionais, tinham todas as respostas para os problemas educacionais: os alunos não sabem, não estudam, não têm preparação. As perguntas, entretanto, mudaram. Como trabalham os professores com a diversidade cultural e epistemológica? Que novas linguagens estruturam a sua prática pedagógica? Como promovem a interculturalidade, quer do ponto de vista epistemológico quer antropológico? Qual o modelo de formação continuada tendo em consideração que os professores em serviço foram formados para um ensino tradicional?

A formação continuada dos professores, transformou-se num direito reconhecido e numa ideologia que pretende associar qualidade e realização individual e profissional a produtividade e desenvolvimento. Aparece, como solução para os problemas mais complexos da sociedade atual e para alguns dos problemas que afetam a educação, seja ao nível básico ou superior. É, como defende Sacristán (1999), uma das pedras angulares imprescindíveis em qualquer intento de renovação. Faremos uma reflexão, a partir da literatura publicada nos últimos anos pelos diversos teóricos brasileiros, europeus e de outros países da América Latina, sobre a formação continuada dos professores da educação superior e estabeleceremos uma relação com a respetiva prática pedagógica. Trata-se de pensar sobre os novos modelos de educação superior e saber em que medida a formação inicial dos professores, de caráter tradicional, não estará desajustada aos novos públicos que frequentam as novas universidades exigindo, por isso, uma formação continuada numa relação estreita com a pesquisa, ensino e extensão. Quando nos referimos à formação tradicional, queremos dizer que o professor, no passado, era preparado para ministrar conteúdos, ensinar a todos como se fossem um só e, mais do que isso, para ser capaz de avaliar o que "tinha ensinado". O professor era preparado, utilizando a terminologia freiriana, para uma "educação bancária", apontando para a neutralidade do ato educativo, legitimando a importância de manter a cultura erudita e nacional, que podemos caracterizar por perspectiva monocultural, também denominada por Cortesão (2011) de "daltonismo cultural", cuja prática não é sensível à "heterogeneidade" e ao "arco íris de culturas" que envolvem os alunos.

Pensamos que novas linguagens, decorrentes das profundas transformações científicas, tecnológicas, culturais, sociais e educacionais, invadiram o sistema educativo. No que diz respeito às transformações sociais, elas decorrem da globalização hegemônica e dos seus efeitos nas sociedades e nas realidades locais; decorrem, 
também, das novas tecnologias que invadiram todos os espaços sociais e educativos; decorrem, ainda, dos hibridismos culturais, da multiculturalidade que, cada vez mais, caracterizam as sociedades contemporâneas globalizadas.

Nóvoa (2000) enfatiza a necessidade "do fazer reflexivo do professor universitário, mediante trabalhos de discussão com acompanhamento de grupos, visando instaurar rotinas de partilha no interior das universidades". (p. 131) A ruptura com o individualismo, constitui resposta aos desafios da atividade docente. A nova relação que os estudantes têm com a quantidade de informações e com o conhecimento pode gerar uma alteração mortífera no triângulo pedagógico: professor-estudante-saber. O professor, utilizando a expressão de Nóvoa (2000), corre o risco de ocupar o "lugar do morto", de ser o terceiro-excluído, no caso de não se adaptar às inúmeras transformações tecnológicas e às alterações produzidas nos próprios espaços educativos decorrentes da diversidade cultural que hoje existe no ensino superior.

Os professores são confrontados na sua prática docente e de pesquisa com as exigências das grandes agências internacionais de regulação e avaliação das universidades: OCDE, OMC, BM, FMI, UNESCO. Uma nova língua invadiu os espaços educativos e universitários: indicadores de produção, prestação de contas (accountability), sistemas de acreditação, critérios de aferição, performances, performatividade ${ }^{1}$, standards etc. Estas linguagens não são inocentes: elas têm o objetivo de transformar as instituições universitárias num mercado produtor de bens simbólicos - o conhecimento - tendo em vista a sua venda e o seu consumo. A educação transforma-se, assim, num produto de consumo que deverá ser rentável. Em oposição a estas novas linguagens surgem novos conceitos que exigem do professor compromissos políticos e educativos que se situam na contramão das exigências neoliberais: o professor multicultural em oposição ao monocultural; a reflexividade, crítica e problematização em oposição a um determinismo educativo; a atividade colaborativa e de partilha em oposição ao individualismo académico; a promoção da interculturalidade em oposição ao monoculturalismo; o investimento na pesquisa e na criatividade como núcleo central da atividade docente e da prática pedagógica em oposição à "educação bancária"; a inclusão da diversidade cultural e epistemológica em oposição a uma visão colonial do conhecimento; a educação como promoção de valores de respeito, solidariedade, democracia contra todas as formas de exclusão, racismo, discriminação e elitismos.

\section{Multiculturalismo e Interculturalismo: Reflexões e perspectivas}

As sociedades contemporâneas são sociedades multiculturais. O multiculturalismo não é um fenômeno recente. As culturas, ao longo da história, sempre tiveram contatos entre si, gerando fenómenos de hibridação² intercultural. Como assinala Canclini (2008), já não basta dizer que não há identidades que se caracterizam por essências 
estáveis e a-históricas, nem entendê-las como as formas em que as comunidades se imaginam e constroem narrativas sobre as suas origens e histórias. Num mundo tão fluidamente interconectado, as sedimentações identitárias organizadas em conjuntos históricos mais ou menos estáveis, se reestruturam dando lugar a conjuntos interétnicos, transclassistas e transnacionais. Uma sociedade multicultural não significa que seja intercultural. O interculturalismo é outro desafio que se coloca às sociedades contemporâneas e, especificamente, à educação tendo em vista a construção/reconstrução das sociedades permeadas pela diversidade. Refletir sobre o multiculturalismo e interculturalismo implica tecer algumas considerações relativas à profissão docente e à prática pedagógica. Para Freire (1992), os processos de ensino e aprendizagem carecem, de maior flexibilidade para satisfazer as diferentes capacidades e interesses de alunos heterogêneos.

Uma das questões que norteará este estudo é a própria definição dos conceitos de multiculturalismo e interculturalismo. Faremos uma reflexão com alguns dos autores que consideramos relevantes: Walsh (2000; 2005; 2012; 2013; 2014; 2015); Santos, (2003); Hall (2010).

Para Hall (2010), o multiculturalismo é entendido como estratégias e políticas adotadas para governar ou administrar os problemas da diversidade e a multiplicidade que existem nas sociedades multiculturais com a sua variedade de distinções: conservador, liberal, pluralista, comercial, corporativo e critico-radical. O multiculturalismo crítico é apenas uma crítica e uma resistência ao modo de funcionamento da sociedade denominada "multicultural".

Boaventura Santos (2013) defende a ideia de que "uma das formas de pensar a globalização é pensar em modos alternativos de pensar, é pensar em culturas alternativas, em conhecimentos alternativos, os quais só podem, naturalmente, ser reconhecidos se tomarmos uma atitude de multiculturalismo ativo e progressista" (p. 11). Refere-se ao multiculturalismo como um conceito contestado:

multiculturalismo designa, originalmente, a coexistência de formas culturais ou de grupos caracterizados por culturas diferentes no seio de sociedades modernas. (...) existem diferentes noções de multiculturalismo, nem todas de sentido emancipatório. O termo apresenta as mesmas dificuldades e potencialidades do conceito de cultura, um conceito central das humanidades e das ciências sociais e que, nas últimas décadas se tornou um terreno explícito de lutas políticas.

Para Santos (2004), podemos explorar o multiculturalismo emancipatório, que "pode continuar a ser associado a conteúdos e projetos emancipatórios e contra-hegemônicos", baseando-se " no reconhecimento da diferença e do direito à diferença 
e da coexistência ou construção de uma vida em comum para além de diferenças de vários tipos." (p. 25).

Catherine Walsh (2005, p. 5), na mesma linha, afirma que "o multiculturalismo é, essencialmente, um termo descritivo. Normalmente, refere-se à multiplicidade de culturas que existem dentro de um determinado espaço, seja local, regional, nacional ou internacional, sem necessariamente uma relação entre eles." Para a autora, essa perpectiva multicultural, ocorre:

no contexto de países ocidentais, como os Estados Unidos, onde as minorias nacionais (negros e índios) coexistem com vários grupos de imigrantes, minorias involuntárias como porto-riquenhos e chicanos, e brancos, todos descendentes de outros países, principalmente os europeus; ou, como na Europa, onde a imigração foi recentemente ampliada. (p. 5)

Conforme observado, o conceito de multiculturalismo é polissémico. Para Candau (2008) "entre igualdade e diferença, isto é, da passagem da afirmação da igualdade ou da diferença para a da igualdade na diferença" (p. 49), são incontáveis as opiniões sobre as vertentes multiculturais. É primordial considerarmos que nenhuma cultura é pura, nesse sentido, Santos propõe o "aumento da consciência de incompletude cultural como uma das tarefas prévias à construção de uma concepção emancipadora e multicultural dos direitos humanos." (Santos, 1997, p. 114).

No que se refere à interculturalidade, Walsh afirma que pensar a interculturalidade a partir do "contexto europeu não é o mesmo que a pensar na América do Sul, onde as aspirações de dominação do mundo, o surgimento do mercado global e a imposição da modernidade e seu outro lado, a colonialidade, tomou forma prática e sentido" (2012, p. 62).

Para a autora (2005, p. 9), "a interculturalidade é diferente no que diz respeito a complexas relações, negociações e trocas culturais, e procura desenvolver uma interação entre pessoas, conhecimentos e práticas culturalmente diferentes." Sua perspectiva intercultural não pode ser reduzida a uma simples mistura, ou fusão, combinação híbrida de elementos, tradições, características ou práticas culturalmente diferentes.

Em cenários de multiculturalidade, os desafios que se colocam aos professores e educadores são enormes em termos de formação e abrem horizontes epistemológicos e axiológicos impensáveis no âmbito do tradicional paradigma de formação docente. Os fenômenos da multiculturalidade e da interculturalidade constituem importantes fatores de mudança no contexto nacional e internacional, quer seja a nível individual quer coletivo.

A interculturalidade implica no reconhecimento das diferenças culturais, fator fundamental do diálogo entre as culturas. Walsh (2012; 2013, 2014, 2015), destaca três 
perspectivas para o conceito de interculturalidade: a interculturalidade relacional vista como o intercâmbio cultural pré-estabelecido entre os diferentes grupos étnico-culturais que convivem no mesmo espaço geográfico; a interculturalidade funcional que aposta no reconhecimento da diversidade sócio cultural e nas diferenças existentes, no respeito e tolerância; e a interculturalidade crítica, cujas diferenças se constroem dentro de uma matriz de poder colonial, racializado e hierarquizado, que aposta, não apenas nas relações culturais, mas por abolição das estruturas e dispositivos de poder que mantêm a desigualdade, a inferiorização, a racialização e a discriminação. Do ponto de vista institucional, as estruturas de dominação de origem colonial constituem verdadeiros obstáculos à interculturalidade.

As políticas neoliberais, que abordaremos em seguida, constituem obstáculos reais à afirmação de uma universidade plural, promotora de uma democracia cognitiva. A criação de novas linguagens e novos discursos, ligados à eficácia e à prestação de contas por parte dos professores, promove a competitividade e o individualismo impedindo uma reflexão colaborativa sobre a prática pedagógica.

\section{As agendas neoliberais: novas linguagens e reflexos na educação}

Em termos genéricos e globais, o neoliberalismo decorre da filosofia liberal dos séculos XVII e XVIII cujos principais promotores foram Rousseau, Locke, Hobbes e Smith. A apologia do individualismo, da democracia burguesa e da defesa da propriedade privada constituem direitos inalienáveis do cidadão, tendo o Estado o dever e a função de proteger a propriedade privada e regular os interesses individuais. O neoliberalismo, fundamenta-se nos grandes princípios do liberalismo e nasce nos EUA, tendo como principais protagonistas Hayeck e Friedman. O pensamento neoliberal responsabiliza o Estado pelas anomalias que existem numa sociedade, pelo atraso econômico, pelo aumento de desemprego, pela inflação e, até, pela flutuação dos juros e da moeda. A entrega dos sectores fundamentais da economia nacional ao sector privado e, atualmente, aos grandes monopólios econômicos e financeiros internacionais, constitui a "garantia infalível" do progresso econômico e social e da criação de uma espécie de "maravilhoso mundo novo". De acordo com Robertson (2007, p. 14-15), a mobilização das ideias neoliberais implicadas na reorganização das sociedades e dos sectores educativos é um projeto de classe norteado por três objetivos fundamentais:

(i) a redistribuição da riqueza pelas elites dirigentes por intermédio de novas formas de governação; ii) a transformação dos sistemas educativos de modo a que a produção de trabalhadores para a economia seja o seu mandato primeiro; iii) o colapso da educação como monopólio do sector público, permitindo a abertura do investimento estratégico às empresas 
lucrativas. A realização destes objetivos exige a ruptura dos interesses institucionalizados dos professores, dos sindicatos dos professores e dos sectores da sociedade civil que defendem a educação como um bem público.

Assim, pode afirmar-se que a globalização neoliberal reconfigurou o mundo, incluindo o mundo da educação. A interferência das políticas neoliberais na educação alterou o seu objetivo fundamental - formar cidadãos críticos -, para assumir a formação de estudantes criativos e eficientes para o mercado de trabalho que possam contribuir para a resolução de problemas numa economia global e competitiva. Por outro lado, os professores deixaram de ser, essencialmente, professores (no sentido tradicional do termo) para reconfigurarem a sua identidade ajustada ao mercado de consumo de bens. De professores, passaram a funcionários públicos, "burocratas e domesticadores das mentes", preocupados, fundamentalmente, com a sua avaliação, dimensão essencial para a progressão na carreira.

A eficácia no trabalho, a competitividade, performatividade e a performance dos professores e das organizações constituem as dimensões essenciais da prestação de contas (accountability). "Performance entendida como medida de produtividade e de desempenho e performatividade como tecnologia, cultura e modo de regulação" (Ball, 2010, p. 37). Este quadro marginaliza por completo o investimento numa educação democrática de qualidade e em práticas tendentes a incluir os grupos sociais mais desfavorecidos social e economicamente. Como refere Lyotard, (1984, p. 46), "a performance estabelece uma equação entre riqueza, eficácia e verdade." O verdadeiro é o que é eficaz e o que gera mais riqueza, independentemente das aprendizagens e do nível de formação dos estudantes e da qualidade formativa dos professores. Um conjunto de tarefas substitui a tradicional função docente: reuniões de avaliação, avaliação dos pares, relatórios, preenchimento de formulários para promoção na carreira, construção de portfólios, produtivismo, construção de gráficos e bases de dados, contabilidade de acordo com critérios e indicadores de produção, pedidos de financiamento para pesquisas. As aprendizagens dos alunos deixaram de ser o núcleo central da atividade docente.

Neste contexto, o Estado demitiu-se das suas funções de regulação e de financiamento da educação para dar lugar ao mercado; os alunos deixaram de ser estudantes e passaram a ser consumidores. A educação deixou de ser um dever do Estado e um direito dos cidadãos para passar a ser um serviço que tem custos, a serem pagos pelos consumidores. Robertson (2007, p. 30) refere a este propósito:

Silenciosamente, a educação rapidamente se comercializou e tornou-se num enorme negócio, protegido por regulações globais. Há uma pressão 
cada vez maior sobre os governos nacionais (por exemplo, da OCDE e do Banco Mundial) para que acabem com os prejuízos e deixem de tentar transformar os arcaicos, burocráticos e difíceis sistemas de educação (e os seus professores) para se passar a uma solução tecnológica.

Perante o cenário anteriormente descrito, formas de resistência vão surgindo, sobretudo no Brasil e noutros países da América Latina. Os novos modelos de educação superior, de que salientamos a Universidade Federal do ABC, constituem, nos seus princípios epistemológicos, formas de resistência ao modelo de educação neoliberal. Resta saber se é possível, no atual quadro político e económico e no âmbito de uma globalização avassaladora, resistir às investidas do poder financeiro e das agências internacionais multilaterais que produzem instrumentos supranacionais de controlo e certificação da "qualidade" da educação. (Dias Sobrinho, 2012). A qualidade da educação superior, refere o autor, "deve corresponder à qualidade definida pelos atores supranacionais do mundo científico, de acordo com os imperativos da economia globalizada." (p. 26) Questiona-se, então, qual o tipo de formação dos professores da educação superior para responderem, por um lado, aos imperativos das agências internacionais e da economia globalizada e, por outro, às necessidades e exigências sociais de inclusão da diversidade social e cultural, decorrente dos novos públicos que frequentam a universidade? É a reflexão sobre essa temática que faremos a seguir.

\section{Do professor monocultural ao professor intercultural}

Os capítulos anteriores permitiram uma importante caracterização do Multiculturalismo, do Interculturalismo e também do neoliberalismo enquanto modelo económico e político e que reconfigurou o mundo, a educação, as relações económicas e interpessoais, impondo novas linguagens.

Face à diversidade de públicos que frequentam as instituições de educação e às diferenças culturais; perante o célere desenvolvimento das tecnologias de comunicação e informação e a sua progressiva "democratização" em termos de acesso, questionamos se ainda faz sentido a existência do professor monocultural, tradutor e reprodutor de uma cultura e do conhecimento científico dominantes. Em síntese, é o que pode ser intitulado de reprodução do saber no desempenho profissional dos professores. Aos olhos de Cortesão (2011, p.16-17):

os professores que no seu trabalho são 'tradutores' do saber científico produzido por outrem (...); os que ensinam um 'ofício de investigador' de acordo com uma actuação semelhante à de um 'treinador de um atleta 
de alta competição' (...) e ainda os que admitem que ele pode ter o papel que se aproxima do de um investigador-actor crítico (...).

A diversidade cultural e as relações interculturais, fazem hoje parte e integrarão, cada vez mais, todos os cenários educativos e contextos sociais do país. Perante a diversidade cultural existente nas instituições educativas, o paradigma cultural dominante, de caráter eurocêntrico perpassa os discursos e práticas dos professores. Nesta linha de pensamento, Cortesão (2011, p. 45-46) afirma que "o professor monocultural" ainda é visto como "aquele que é competente, portanto "sabe", que domina conteúdos científicos que (arbitrariamente) são considerados como curricularmente imprescindíveis."

No centro das observações a seguir está, em primeiro lugar, o que deve ser compreendido pelo conceito de "professor monocultural" e, em seguida, se e até que ponto podem contribuir para o diálogo e aprendizado intercultural. Para Cortesão, o professor monocultural (p. 50) tem por alicerce a neutralidade como prática educativa, assente em materiais e metodologias padronizadas, priorizando a estabilidade conduzida por privilegiar a cultura erudita e nacional. Um padrão de profissional que concebe "os alunos como iguais em direitos e deveres" promovendo maneiras igualitárias de ensino, ou seja, permanece, como traduz Santos, "indiferente à diferença" de seus alunos, de sua cultura, retido no que a autora chama de "daltonismo cultural" (p. 16). Para este professor ainda constitui prioridade a transmissão de saberes científicos considerados importantes, o que nos permite revisitar o conceito de "educação bancária" de Paulo Freire, cuja prática não permite aos alunos desenvolver a criticidade, dado que tem como fundamento uma concepção tradicional, dualista e autoritária de educação que considera o estudante como um ser passivo e receptivo.

$\mathrm{Na}$ contramão do professor monocultural, a autora traz o professor "intermulticultural" (p. 61), o professor para uma "cidadania colorida, consciente do arco-íris de culturas" efetivo nas instituições de ensino, consciente que estes locais são espaços de "práticas conflituais, de cruzamento de diferentes poderes, interesses e valores", compostos por um círculo heterogêneo de sujeitos, cujo principal abraçamento é a "aceitação e rentabilização da diferença". Na mesma perspectiva, Freire (2008, p. 32) considera que "quanto mais conscientizados nos tornamos", tanto mais somos capazes de anunciar, denunciar, refletir e tomar atitudes que gerem transformação. Refere o autor que o processo de ensino não pode ser monocultural, verticalizado e sim praticado de forma horizontal entre o formador e o formando. Deve buscar coletivamente uma educação conscientizadora e libertadora, em uma troca ininterrupta de conhecimentos, como um circulo virtuoso que jamais termina. É necessário que o formador crie possibilidades para que o sujeito, que se apresenta em um nível de conhecimento "comum" transite para um nível de conhecimento "crítico"- chegue, portanto, à conscientização, pressuposto fundamental para a libertação. 
É incontornável pensar na participação dos professores em equipes colaborativas de reflexão sobre as ações que vão desenvolvendo e que sejam pontos de partida para a organização de futuras intervenções, que busquem estratégias de práticas educativas interculturais, associadas ao professor investigador, que tragam as pesquisas e seus resultados para o ambiente em que estão inseridos como condição imprescindível de aprendizagem, que as compartilhem, assumindo um papel interventivo na reconfiguração do currículo e não apenas como meros receptores e reprodutores de conhecimento.

As manifestações multiculturais nas análises educacionais trouxeram importantes desafios às pesquisas sobre o conhecimento. As práticas curriculares e de formação docente voltadas à construção de identidades discente e docente interculturalmente comprometidas com o ensino/aprendizagem, visam promover o respeito à diferença e à pluralidade cultural. Porém, Cortesão (2011, pp. 51-52) afirma que:

Os docentes universitários ensinam geralmente como foram ensinados, garantindo pela sua prática uma transmissão mais ou menos eficiente de saberes e uma socialização idêntica àquela de que eles próprios foram objeto. E note-se que, enquanto isto é frequentemente praticado e até defendido no Ensino Universitário, nos níveis mais baixos do Sistema Educativo, embora geralmente se mantenham práticas muito tradicionais, não é pelo menos tão frequente que os professores e instituições sejam capazes de defender este tipo de atuação.

Para Cortesão (2011), os ensinos secundário ${ }^{3}$ e universitário permanecem guiados pelo monoculturalismo, contrariamente aos ensinos infantil e básico onde se põem em prática as pedagogias ativas, possibilitantes de abordagens multi e interculturais. Atenta-se a lacunas que se referem à pesquisa como um locus de reflexão e de proposições de planos e projetos capazes de articularem discussões teóricas, iniciativas concretas no âmbito da formação continuada dos docentes, voltadas à união entre esta formação continuada, a pluralidade cultural e a prática pedagógica.

Neste redesenho, assim como a democratização da escola, a educação também deve ser considerada como uma grande e importante luta. Os docentes carecem conscientizar-se de que, a cada dia, surgem novos desafios impostos pela necessidade da ampliação da educação no Brasil, decorrentes das transformações céleres que acontecem na sociedade, tal como o investimento na formação docente e na qualidade da educação. Se mudaram as perguntas, urge que despontem novas respostas, e em retorno a este contexto ofensivo neoliberal, só se rompe com este suposto de corporativismo e inflexibilidade da categoria docente frente a este mundo globalizado, por meio de formação especifica e continuada, da pesquisa colaborativa e por meio de ações ideológicas harmônicas e conjuntas. 


\section{Considerações Finais}

Nos últimos 30 anos, o mundo mudou consideravelmente. É fundamental, no entanto, reconhecer as mudanças ocasionadas pela globalização, identificar as surpreendentes transformações movidas pelo advento das Tecnologias da Informação e Comunicação (TICs), já que não podemos negar que as TICs e a educação estão profundamente ligadas e os educadores que ainda resistem a tal progresso e às inovações que elas possibilitam, se reduzem a profissionais superados e inadequados aos anseios das instituições de ensino, da sociedade, mas, sobretudo dos estudantes.

Não se pode deixar de considerar as ideologias neoliberais, que tentam de uma forma ou de outra convencer a todo custo as nações subordinadas a aceitarem suas determinações enquanto modelo económico e político e conforme dito anteriormente, também contribuíram para a reconfiguração do mundo educativo, para além das relações económicas e interpessoais, impondo, como já reportamos, novas linguagens ligadas à eficácia, à performatividade e à prestação de contas (accountability).

Deve-se também contemplar o multiculturalismo resultante dos processos migratórios, pois a diversidade cultural e as relações interculturais fazem hoje parte integrante de todos os contextos sociais do país, com implicações no setor educacional. Neste sentido, fazendo uma releitura a tudo o que fôra abordado neste texto, questionamos: "mas e a educação mudou?" Memoramos o horizonte freiriano e sua constante preocupação com a construção de uma educação profundamente comprometida com o respeito aos educandos, seus saberes, sua cultura, intentando a liberdade e emancipação dos povos.

Este conjunto de fatores nos leva a refletir sobre a ampla importância da formação continuada do professor contemporâneo, pois conforme mencionado anteriormente, ela é tida como uma possível solução para os problemas mais complexos da sociedade atual e para alguns dos problemas que afetam a educação, seja em nível básico ou superior. Reconhecemos que é essencial que esta formação continuada traga discussões, pesquisa e reflexão sobre o "multi/interculturalismo", como propõe Cortesão, com o objetivo de desenvolver uma educação crítica, capaz de superar a desigualdade e exclusão social, aprofundadas pelo modelo hegemônico e monocultural de educação.

Concluímos que as respostas para as novas perguntas surgirão como resultado de uma formação continuada aliada à pesquisa, ao ensino e a projetos de extensão. A articulação da formação continuada com projetos de pesquisa interinstitucionais e internacionais inovadores e com a dimensão pedagógica contribuirá para a abertura de caminhos instigantes e desafiadores no âmbito da ação pedagógico-didática, propiciando a todos os sujeitos envolvidos na educação processos de reflexão crítica e problematizante que permitam construir uma escola e uma universidade mais de- 
mocráticas e mais justas e, consequentemente, mais ligadas à realidade sociocultural plural que caracteriza as sociedades contemporâneas e, particularmente, a sociedade brasileira.

\section{Notas}

1 St. Ball $(2001,2002,2004)$ utiliza-se da noção de performatividade refletindo implicações do neoliberalismo na reforma educacional. Denuncia as potências económicas globais que têm imposto um novo gerencialismo das instituições educativas. Ball (2002, p. 9) afirma: "no novo mundo das organizações performativas [...] as bases de dados, as reuniões de avaliação, a revisão anual, a redação de relatórios e a candidatura a promoções, inspeções e comparação com pares estão em primeiro lugar." valores gerenciais se impõ̃em ao currículo, conduz e delimita fronteiras, administrativas, pedagógicas e, comportamentais. A filosofia da performatividade contradiz os princípios da democracia e justiça curriculares e das relações interpessoais, instituindo a cultura do individualismo e da competitividade patológica. Novos papéis são criados em função de novas identidades docentes reconstruídas: os professores passam a ser produtores de bens e serviços; empreendedores educacionais e gestores sujeitos a avaliações regulares de desempenho. Novas formas de disciplina emergem da competitividade, eficiência e produtividade. (Ball, 2002).

2 Para Canclini (2008, p. XIX) hibridação é "um conjunto de processos socioculturais nos quais estruturas ou práticas discretas, que existiam de forma separada, se combinam para gerar novas estruturas, objetos e práticas." Considera o autor que as estruturas denominadas discretas foram, elas próprias, o resultado de hibridações e, por isso, não poderão ser consideradas fontes puras. Parte do pressuposto de que, em nenhum momento histórico, existiram culturas puras.

3 Corresponde ao Ensino Médio, no Brasil.

\section{Referências Bibliográficas}

Ball, S. (2001). Diretrizes políticas globais e relações políticas locais em educação. Currículo sem Fronteiras, p. 99-116.

Ball, S. (2002). Reformar escolas/reformar professores e os terrores da performatividade. Revista Portuguesa de Educação, 15 (2), pp. 3-23.

Ball, S. (2004) Performatividade, privatização e pós-estado de bem-estar. Educação e Sociedade, 89 (XXV), 23-35.

Ball, S. (2010) Performatividades e fabricações na economia educacional: rumo a uma sociedade performativa. Educação \& Realidade, Porto Alegre, 35, p. 37-55.

Canclini, N. G. (2008). Culturas Híbridas. Estratégias para entrar e sair da modernidade. São Paulo: Edusp.

Candau, V. (2008). Direitos humanos, educação e interculturalidade: as tensões entre igualdade e diferença. Revista Brasileira de Educação, n. 37, pp. 44-57.

Cortesão. L.(2011). Ser professor: um ofício em risco de extinção? (3. ${ }^{a}$ ed.) São Paulo: Cortez.

Dias Sobrinho, J. (2012). Acreditación en América Latina: crisis de la educación superior y distintas fases de la calidad. In Rosario Muños et all. La Acreditación de la Educación Superior en Iberoamérica. La gestión de la calidad de los programas educativos. Tensiones, desencuentros, conflictos y resultados, I. Bloomington: Red De Académicos de Iberoamérica, A. C..

Freire, P. (1992). Pedagogia da esperança: um reencontro com a pedagogia do oprimido. Rio de Janeiro: Paz e Terra. 
Freire, P. (2008). Conscientização: teoria e prática da libertação: uma introdução ao pensamento de Paulo Freire. São Paulo: Centauro.

Galeano, E. (1994). As palavras andantes. Porto Alegre: L\&PM.

Hall, S. (2010). Sin garantías: trayectorias y problemáticas en estudios culturales. Quito: Envión Editores. Lyotard, F. (1984). A condição Pós-Moderna. Lisboa: Gradiva.

Nóvoa, A. (2000). Universidade e Formação Docente. Interface - Comunicação, Saúde, Educação, 7. Entrevista realizada em 18 de abril de 2000 pelas professoras Miriam Celí Pimentel Porto Foresti e Maria Lúcia Toralles Pereira.

Robertson, S. L. (2007). "Reconstruir o Mundo": Neoliberalismo, a Transformação da Educação e da profissão (do) professor. Revista Lusófona de Educação, 9, 13-39.

Sacristán, J. G. (1999). Poderes Instáveis em Educação. Porto Alegre: Artes Médicas.

Santos, B. S. (2003). Dilemas do nosso tempo: globalização, multiculturalismo e conhecimento (entrevista com Boaventura de Souza Santos). Currículo sem Fronteiras, 2, pp.5-23.

Santos, B. S., Nunes, J. A. (2004). Introdução: para ampliar o cânone do reconhecimento, da diferença e da igualdade. In: Santos, B. S. Reconhecer para Libertar: os caminhos do cosmopolitismo multicultural. Porto: Edições Afrontamento.

Santos, B. S. (1997). Por uma Concepção Multicultural dos Direitos Humanos. Revista Critica de Ciências Sociais, 48, 11-32.

Walsh, C. (2000). Significados y políticas conflictivas. Revista Nueva Sociedad (Caracas), 165, 121-133.

Walsh, C. (2005). La educación intercultural en la educación. Lima: Ministerio de Educación, Mimeografado.

Walsh, C. (2012). Etnoeducación e interculturalidad en perspectiva decolonial. Cuarto Seminario Internacional "Etnoeducacion e Interculturalidad. Perspectivas Afrodescendientes. Lima.

Walsh, C. (2013). Pedagogías Decoloniales. Prácticas insurgentes de resistir, (re)existir y (re)vivir. Quito: Ediciones Abya-Ayala.

Walsh, C. (2014). Lo pedagógico y lo decolonial: entretejiendo caminos. Quito: Qurétaro.

Walsh, C. (2015). Sobre el género y su modo-muy-otro. In Quintero, P. (2015). Alternativas descoloniales al capitalismo colonial/moderno (pp. 165-182). Buenos Aires: Ediciones del Signo. 
Sandra Gomes

Mestranda em Educação no Programa de Pós- Graduação em Educação (PPGE) da Universidade Nove de Julho.

Email: san.r.gomes@hotmail.com

Manuel Tavares

Doutorado em Filosofia. Professor do Programa de Pós-Graduação em Educação (PPGE) da Universidade Nove de Julho.

Email: manuel.tavares@outlook.com.br

Correspondência

Manuel Tavares

R. Itauna, 74 - Vila Maria Baixa, São Paulo - SP,

2111-030, Brasil

Data de submissão: Janeiro de 2016

Data de avaliaçãoo; Fevereiro de 2017

Data de publicação: Julho 2016 